\title{
EDUCAÇÃO AMBIENTAL EM ESCOLAS: SENSIBILIZANDO O PROFESSOR DE PEQUENOS MUNICÍPIOS
}

\author{
Nilva de Araujo Pedron ${ }^{1}$, Marcelo Barcellos da Rosa² \\ ${ }^{1}$ Especialista em Educação Ambiental - UFSM. \\ 2 Professor do Curso de Especialização em Educação Ambiental da UFSM. \\ nilvapedron@hotmail.com, marcelobdarosa@gmail.com
}

\section{RESUMO}

A Educação Ambiental deve ser encarada como de extrema relevância na formação dos alunos e á única com um cantinho exclusivo na Constituição em vigor, considerando os aspectos sociais, econômicos, políticos, culturais e éticos, além do ecológico, preparando e desenvolvendo o educando para a melhor qualidade de vida e seu pleno exercício de cidadania. Esta monografia tem como objetivo realizar um levantamento bibliográfico acerca do conceito, finalidade e funções da educação ambiental à luz de uma prática que consiga fomentar a formação da cidadania dos educandos, bem como apresentar os resultados de uma entrevista, de caráter qualitativo, realizada com professores da cidade de Cacequi, RS, de modo se identificar suas experiências em educação ambiental, bem como trazer a tona as inquietações que impossibilitam uma prática totalmente eficiente da mesma. Observa-se no findar desta pesquisa que questões como falta de formação, discussão, leitura, de regulamentações político-pedagógicas são alguns dos inúmeros fatores que impossibilitam que a educação ambiental ainda sirva como um alicerce e prática de cidadania.

Palavras-chave: Ambiente, cidadania, escola.

\begin{abstract}
Environmental education should be seen as extremely important in the training of students and be one with a unique corner in the Constitution in force, taking into consideration social, economic, political, cultural and ethical, as well as ecological, preparing and developing the student to better quality of life and full exercise of citizenship. This monograph aims to do a survey about the concept, purpose and functions of environmental education in the light of a practice that can foster the development of citizenship among the students, as well as present the results of an interview, qualitative, conducted among teachers City Cacequi, RS, in order to identify their experiences in environmental education, as well as bring out the concerns that preclude a fully practice it efficiently. Notes on the ending of this research that issues such as lack of training, discussion, reading, political and pedagogical rules are some of the many factors that prevent environmental education also serves as a foundation and practice of citizenship.
\end{abstract}

Key words: Environment, citizenship, school. 


\section{INTRODUÇÃO}

A Educação Ambiental é a única disciplina com espaço exclusivo na Constituição em vigor, a de 1988 - o artigo 225, que estabelece como incumbência do Poder Público "promover a Educação Ambiental em todos os níveis de ensino", tornando-se autônoma e obrigatória, mas fora do currículo escolar. Assim, costuma ser ministrada como atividade extracurricular ou integrada as Ciências, causando insegurança, divergências e confundidas muitas vezes com o ensino de Ecologia.

A questão ambiental não pode ser ensinada apenas pelo enfoque biológico sob pena de virar realmente meio ambiente, a abordagem é mais integrada, pois além do aspecto ecológico, consideram aspectos sociais, econômicos, políticos, culturais e éticos.

A produção de conhecimentos na busca da cidadania percebe-se os problemas ambientais, identificando soluções com participação comunitária, passa a tomar parte em ações que conduzam à melhoria do meio ambiente.

A população está cada vez mais envolvida com as novas tecnologias e com cenários urbanos perdendo desta maneira, a relação natural que tinham com a terra e suas culturas. Os jovens e os valores relacionados com a natureza não têm mais pontos de referência na atual sociedade moderna.

O relacionamento da humanidade com a natureza, que teve início com um mínimo de interferência nos ecossistemas, tem hoje culminado numa forte pressão exercida sobre os recursos naturais.

Atualmente, são comuns à contaminação dos cursos de água, a poluição atmosférica, a devastação das florestas, a caça indiscriminada e a redução ou mesmo destruição dos habitats faunísticos, além de muitas outras formas de agressão ao meio ambiente.

Dentro deste contexto, é clara a necessidade de mudar o comportamento do homem em relação à natureza, no sentido de promover sob um modelo de desenvolvimento sustentável (processo que assegura uma gestão responsável dos recursos do planeta de forma a preservar os interesses das gerações futuras e, ao mesmo tempo atender as necessidades das gerações atuais), a compatibilização de práticas econômicas e conservacionistas, com reflexos positivos evidentes junto à qualidade de vida de todos.

O presente trabalho aborda esta questão, sugerindo que a Educação Ambiental deva ser um processo educacional desde seu início, e que, portanto deva ser norteado pelos mesmos princípios que a Educação Ambiental propõe, buscando mudanças em seu currículo e metodologia que possam não só diminuir tal influência, mas talvez invertê-la por uma que traga conseqüências benéficas ao mesmo.

\section{Conceito de Educação Ambiental}

Educação Ambiental é o nome que historicamente se convencionou dar às práticas educativas relacionadas à questão ambiental. Assim, "Educação Ambiental" designa uma qualidade especial que define uma classe de características que juntas, permitem o reconhecimento de sua identidade, diante de uma Educação que antes não era ambiental. Contudo, desde que se cunhou o termo "Educação Ambiental", diversas classificações e denominações explicitaram as concepções que preencheram de sentido as práticas e reflexões pedagógicas relacionadas à questão ambiental. 
Como lembra Dias (1992), a evolução do conceito de educação ambiental acompanhou a evolução do conceito e da percepção de ambiente. Evoluiu de um enfoque mais ecológico no sentido das ciências biológicas, para uma dimensão que incorpora as contribuições das ciências sociais fundamentais para a melhoria do ambiente humano.

O desafio que se coloca é o de formular uma Educação Ambiental que seja crítica e inovadora em dois níveis - formal e não formal. Assim, a Educação Ambiental deve ser acima de tudo um ato político voltado para a transformação social... (JACOBI, 1998).

\section{Finalidades da Educação Ambiental}

A educação ambiental tornou-se lei em 27 de Abril de 1999. A Lei № 9.795 - Lei da Educação Ambiental, em seu Art. $2^{\circ}$ afirma: "A educação ambiental é um componente essencial e permanente da educação nacional, devendo estar presente, de forma articulada, em todos os níveis e modalidades do processo educativo, em caráter formal e não-formal.

A educação ambiental tenta despertar em todos a consciência de que o ser humano é parte do meio ambiente. Ela tenta superar a visão antropocêntrica, que fez com que o homem se sentisse sempre o centro de tudo esquecendo a importância da natureza, da qual é parte integrante.

Esse processo de sensibilização da comunidade escolar pode fomentar iniciativas que transcendam o ambiente escolar, atingindo tanto o bairro no qual a escola está inserida como comunidades mais afastadas nas quais residam alunos, professores e funcionários estreitando as relações intra e extra-escolar.

O ensino de educação ambiental deve ser pautado no entendimento de questões que não necessariamente são ligados apenas às questões ambientais, mas muitas vezes a questões políticas que refletem no meio natural e na qualidade de vida das pessoas.

A problemática ambiental tem um componente especial. É que: não basta que as pessoas saibam o que fazer, mas o necessário que façam. Não é, portanto, um problema de saber, é um problema de ação. E, para fazer essa ação, claro que precisam saber.

Na proposta da Política de Educação Ambiental está em construção uma teia de formação continuada, refletindo as questões sócias ambientais a partir da realidade local, dialogando com diferentes saberes, construindo e reconstruindo conhecimentos e alternativas às problemáticas sócias ambientais, resignificando as práticas pedagógicas.

Para que haja uma verdadeira educação ambiental é necessária à entrada dos conceitos da sustentabilidade na formação escolar. Isto se aplica tanto à educação infantil até as últimas séries de um curso universitário. Muitos estudiosos da área afirmam que a fase da vida mais importante para o desenvolvimento da cidadania é a infância.

Numa prática educativa voltada para a consciência ambiental, as crianças aprenderiam sobre várias questões, como por exemplo: como usar os recursos naturais de forma responsável, qual é a importância da natureza na vida do homem, como devem ser separados os resíduos de casa, etc.

O governo também tem um papel essencial na aplicação dessas práticas educativas na escola. Ele pode fazer leis, mudar as grades curriculares das escolas da rede pública, iniciar projetos de sustentabilidade aplicados à educação, etc. 


\section{Preocupações Educacionais}

A maior preocupação do professor deve ser a de desenvolver valores, atitudes e posturas éticas, pois os conceitos necessários para tratar de assuntos ambientais aprendidos em outras disciplinas, mostrando aos seus alunos as diferenças entre ambientes equilibrados, saudáveis, e locais poluídos ou degradados. É importante que eles percebam que constatar algum mal não é motivo de desânimo, mas de mobilização da escola e da comunidade para sua solução.

Temos que ter metas de Educação Ambiental para garantir que a população mundial tenha consciência do meio ambiente e se interessar por ele e por seus problemas e que conte com os conhecimentos e atitudes, motivação e desejos necessários para trabalhar individual e coletivamente na busca de soluções dos problemas atuais e para prevenir os que possam aparecer, quebrando paradigmas, tais como:

O desafio que se coloca é de formular uma educação ambiental que seja crítica e inovadora, em dois níveis - formais e não-formal. Assim, a educação ambiental deve ser acima de tudo um ato político voltado para a transformação social. O seu enfoque deve buscar uma perspectiva de ação holística que relaciona o homem, a natureza e o universo, tomando como referência que os recursos naturais se esgotam e que o principal responsável pela sua degradação é o homem.

Para muitos professores, pais, alunos etc., a educação ambiental só pode ser feita quando se sai da sala de aula e se estuda a natureza tal qual ela é. Esta é uma atividade pedagógica muito rica de possibilidades, mas corre-se o risco de tê-la como única atividade possível, quando na verdade é apenas mais uma (REIGOTA, 2006).

A educação ambiental deve ser abordada formalmente de maneira que potencialize o pensar socioambiental, influenciando na cidadania dos indivíduos e, assim, não correrá o risco de ser apresentada como unicamente teoria mecanicista fora do real.

\section{METODOLOGIA}

Esta pesquisa foi subdividida em duas partes distintas: a primeira foi um levantamento bibliográfico destacando a importância da Educação ambiental no exercício da cidadania, que é apresentado no referencial teórico. Na segunda, foi realizada uma entrevista com professores de vários níveis de formação, em escolas municipais, estadual e particular, na cidade de Cacequi/RS, com a finalidade, tanto de se diagnosticar o nível de interesse sobre o tema Educação Ambiental como exercício de cidadania.

A entrevista foi distribuída a 18 professores voluntários, atuantes com alunos de idades e culturas diversificadas, após uma reflexão do assunto por parte da proponente desta pesquisa. 


\section{RESULTADOS E DISCUSSÃO}

Em relação ao levantamento bibliográfico realizado na primeira etapa desta pesquisa, a atenção foi dada a questão conceitual da educação ambiental, bem como as suas finalidades, a fim de se revisitar a literatura especializada. A maior preocpação nesta pesquisa foi de mostrar de forma objetiva de que forma a educação ambiental tem sido abordada, de forma "modesta", dentro do complexo sistema teoria versus prática. Além disso, um referencial teórico é apresentado de forma se tentar visualizar os professores como educadores ambientais de forma mais contundente, onde as relações entre as preocupações educacionais, a cidadania e questões socioambientais são mencionados. Portanto, busca-se uma argumentação e/ou reflexão de que a educação ambiental é uma questão de responsabilidade humana e não se pode separá-la, tanto do exercício da cidadania, quanto da formação do cidadão.

Na segunda etapa desta pesquisa, uma entrevista foi realizada, de modo se extrair de forma mais qualitativa as inquietações dos professores que atuam, tanto com crianças, quanto adolescente no atual cenário de crise sócio ambiental de valores éticos e morais. Houve a participação de professores com as mais variadas formações acadêmicas, que atuam em diferentes anos escolares e com vários anos de experiência em escolas.

De forma organizar as respostas dos entrevistados, as respostas foram compiladas de forma geral, salientando-se as opiniões comuns à maioria dos entrevistados.

De modo geral, observou-se que conceito de Educação ficou definido pela maioria dos entrevistados como sendo o ato de transformar, gerar conhecimentos na busca incessante de possíveis respostas frente à transformação no processo de construção do conhecimento.

Em relação ao tema Educação Ambiental, este se mostrou como um problema a maior parte dos professores, ou por simples desconhecimento do assunto, ou por falta de segurança em abordá-lo. Ou seja, os professores entrevistados revelam suas dificuldades em transmitir tal tema.

"Educação Ambiental é uma forma de discutir conhecimentos com o objetivo de formar uma consciência de desenvolvimento ambiental" (Professora, Ensino Fundamental).

Observa-se que a Educação Ambiental ainda é encarada, pela grande maioria dos professores, apenas como uma forma de consciência ecológica. Questões como mudança de hábitos, perspectivas, concepções, de paradigmas como do consumismo, entre outros, estão ainda longe de serem discutidos entre os pares e quem dirá, repassado aos alunos.

Respostas genéricas como que ...."vivenciar a Educação Ambiental em sua prática escolar concretiza-se com ações como reciclar o lixo, economizar água e luz"... foram uma constante ao longo da entrevista. Nota-se claramente um despreparo, ou falta de formação, discussão, ou de informação por parte dos professores. Aqui cabe ressaltar, que a evolução do processo educativo deve vir acompanhada de um processo de modernização nas leis e forma de se visualizar o ensino. Com o avanço científico e tecnológico que a humanidade bombardeada diariamente, questões como a ignorância coletiva e o analfabetismo funcional já invadem os estabelecimentos de ensino, transformando o complexo processo ensino-aprendizagem como um processo mecanizado e de cumprimento frio de disciplinas. A educação ambiental migra exatamente no sentido oposto, ou seja, no sentido transversal da educação, onde as disciplinas dialogam e se integram.

"Os professores têm a grande responsabilidade de alertar e direcionar soluções ao problema da Educação Ambiental mundialmente conhecido. Orientá-los em sala de aula não é uma tarefa fácil, mas de extrema urgência, visto o grande impacto ecológico que estamos sofrendo com 
os descuidos de nossos antepassados". (Depoimento de uma professora que se negou a preencher o questionário).

A busca constante de soluções para os problemas ambientais considera toda a importância da temática ambiental e a visão integrada do mundo, no tempo e no espaço, sobressaem-se às escolas, como espaços privilegiados na implementação de atividades que propiciem este trabalho, pois isso necessita de atividades de sala de aula e atividades de campo, com ações orientadas em projetos e em processos de participação que levem à autoconfiança, a atitudes positivas e ao comprometimento pessoal com a proteção ambiental implementados de modo interdisciplinar.

Quando questionado a receptividade dos alunos quanto ao tema educação ambiental, foi respondida por uma professora do ensino médio como uma necessidade de sobrevivência e que os alunos sabem que precisam preservar mudando hábitos.

O Planeta Terra passa por grandes modificações ambientais, das quais o ser humano é o grande responsável, e necessita urgentemente despertar para a conscientização e buscar soluções para os problemas ambientais que estão surgindo a cada dia. Com o objetivo de sensibilizar, despertar e compreender as questões ambientais, a Educação Ambiental deve surgir como proposta, que vem sendo discutida em todo o mundo, como forma de desenvolver uma sociedade mais justa e ambientalmente sustentável.

Atualmente, o planejamento interdisciplinar pedagógico está fora da realidade do aluno, mas nem sempre vinculado aos objetivos e procedimentos desgastados da qual a verdadeira realidade exige, apontando a educação ambiental como componente essencial e permanente da educação nacional em todos os níveis e modalidades, tanto do processo formal como não formal, assim como o seu caráter humanista, participativo, democrático que permite entender a complexidade do meio ambiente, que supera os limites da natureza e envolve a interrelação de aspectos econômicos, políticos, culturais, éticos e sociais da dinâmica social, no intuito de construir uma sociedade ambientalmente equilibrada, fundada nos princípios de liberdade, igualdade, solidariedade, democracia, justiça social, responsabilidade e sustentabilidade.

Analisando-se a forma de como os professores de diferentes disciplinas e de diferentes escolas aplicam a Educação Ambiental na rotina diária escolar, integrando o currículo e as novas metodologias pedagógicas, Reigota (1998, p.44), a mais de uma década atrás, afirma que:

A educação Ambiental correu o risco de se tornar, por decreto uma disci-

plina obrigatória no currículo nacional; mas com que os burocratas e oportunistas de plantão não contavam, era encontrar a resistência de profissionais mais conhecedores da área, o que evitou que a mesma se tornasse mais uma banalidade pedagógica, perdendo todo o seu potencial crítico e questionador a respeito das nossas relações cotidianas com a natureza, artes, conhecimento, ciência, instituições, trabalho e com as pessoas que nos rodeiam.

Ambiente é sinônimo de ética e indica o estado das coisas que produzimos continuamente em relação com a vida (natural, artificial, humana, não-humana) com sentido muito amplo. Ambiente e habitação trazem a idéia de complexidade, de interdependência, de fatores socioambientais, de ecossistema, de vida dinâmica em transformação e necessidade de equilíbrio. A cidadania integra todas estas ações.

Uma vida apreciável a todos é uma tendência natural e cultural para a expansão da vida, da biodiversidade e, assim, da consciência. E quando se diz ética ambiental é para lembrar um 
pouco mais da relação dos seres humanos com os seres todo e com o ecossistema em desequilíbrio.

Acredita-se que os objetivos desta monografia foram alcançados e que o caminho a ser percorrido pela educação ambiental na formação do cidadão é longo, árduo, complexo, mas inevitável.

\section{CONCLUSÃO}

A vida é uma troca. O universo responde á nossa violência ou à nossa bênção, cedo o tarde. Em todo o caso "antes tarde do que nunca" para aprender a sustentar-se, ambientar-se, integrar-se, ou seja, inserir-se como cidadão.

A forma mais eficaz de sensibilizar o ser humano é a Educação, pois à medida que se desperta a consciência, pode-se esperar uma atitude transformadora. A mais de três décadas FREIRE já refletia que a "educação é o desenvolvimento de uma consciência crítica que permite ao homem transformar a realidade" e ainda hoje vemos o quão complexo é se mudar o paradigma cultural de que parece que não fazemos parte do meio ambiente.

Enfim, ficam muitas questões sem resposta: Os professores estão se preparando para atuar em Educação Ambiental? Há interesses para que estes conhecimentos estejam no currículo escolar? Qual a solução que buscamos para que esta mudança pedagógica esteja colaborando com o crescimento intelectual e cultural de nossos alunos?

\section{REFERÊNCIAS BIBLIOGRÁFICAS}

AMBIENTAL Educação - Competências para o atuar docente-SILVA, Clotildes Lessa, da ARAúJO, Daniel, organização. Senac-EAD-RS, 2008.

ANDRADE, D. F. Implementação da Educação Ambiental em escolas: uma reflexão. In: Fundação Universidade Federal do Rio Grande. Revista Eletrônica do Mestrado em Educação Ambiental, v. 4.out/nov/dez 2000.

ARROYO Miguel Gonzáles. Pátria Amada, Ignorada. In: Em Aberto. Brasília, 7(37), jan.-mar. 1988.

BRANDÃO, Carlos Rodrigues. O que é educação. São Paulo, Brasiliense, 1994.

CASCINO, F. 1999. Educação Ambiental: Princípios, História, Formação de Professores. Editora SENAC, SP.

CAMARGO, Dulce Maria Pompêo; ZAMBONI, Ernesta. A Criança Novos Tempos, Novos Espaços; a História e a Geografia na Escola. In: Em Aberto. Brasília, 7 (37), jan-mar. 1988.

DIAS, G. F. 2000. Educação Ambiental: Princípios e Práticas. Editora Gaia, 6a. Edição, SP.

DUARTE JUNIOS, J. F. O que é Realidade? São Paulo: Brasiliense, 1984.

EDUCAÇÃO ambiental: curso básico à distância: Educação e educação ambiental II. Coordenação-Geral: Ana Lúcia Tostes de Aquino Leite e Naná Mininni-Medina. Brasília: MMA, 2001. 5 v. $2^{\text {a }}$ edição ampliada.

FREIRE, Paulo. Educação e Mudança. Rio de Janeiro: Paz e Terra, 1981. 


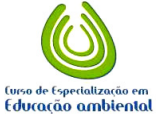

REMOA

GONZÁLEZ, Gaudiano, E. Educación ambiental: história y conceptos a veinte años de Tbilisi. México, DF: Sistemas Técnicos de Edición, 1997.

IBAMA. Educação Ambiental: as grandes orientações da Conferência de Tbilisi. Organizado pela UNESCO. Coleção meio ambiente. Série estudos educação ambiental; edição especial. Brasília: Instituto Brasileiro do Meio Ambiente e dos Recursos Naturais Renováveis, 1998.

JACOBI, Pedro. , OLIVEIRA, F. José. Educação, Meio Ambiente e Cidadania. São Paulo, SMA/CEAM, 1998.

JORNAL MUNDO JOVEM. Junho/1999 n. ㅇ 297 p 78.

LEFF, E. Epistemologia ambiental. Tradução: S. Valenzuela. São Paulo: Cortez, 2001a.

LIPIETZ, A. A ecologia política: solução para a crise da instância política? In: ALIMONDA, H. (Ed.). Ecologia política. Buenos Aires: CLACSO, 2002.

OLIVEIRA, E.M. O Que fazer Interdisciplinar. In: A Educação Ambiental uma possível abordagem. Brasília, Edições IBAMA, 2000.

PÁDUA, S.; TABANEZ, M. (orgs.). Educação ambiental: caminhos trilhados no Brasil. São Paulo: Ipê, 1998.

PIAGET, Jean. Para onde vai à educação. Editora José Olimpio 9a Edição: 1998.

REIGOTA, Marcos. O que é educação ambiental. São Paulo, Brasiliense, 2006.

REVISTA, Nova Escola para professores de primeiro grau, Fundação Vitor Sivita. Editora Abril. São Paulo, ano VII, 59 agosto 1992. p 14.

TEIXEIRA, Anísio. Educação é um direito. Editora Nacional 1968. 